\title{
Characteristic, Emotional, and Behavioral Problems of Street Adolescent in Bandung October-December 2012
}

\author{
Annisa Nurfitriani, ${ }^{1}$ Veranita Pandia, ${ }^{2}$ Guswan Wiwaha ${ }^{3}$ \\ ${ }^{1}$ Faculty of Medicine Universitas Padjadjaran, ${ }^{2}$ Department of Psychiatry Faculty of Medicine, \\ Universitas Padjadjaran/Dr. Hasan Sadikin General Hospital Bandung, ${ }^{3}$ Department of Public \\ Health Faculty of Medicine Universitas Padjadjaran
}

\begin{abstract}
Background: Street adolescents were psychosocial problem that increased in number each year and was worsened by their low-moral subculture-value that could cause them more vulnerable in having emotional and behavioral problems. This study aims to describe the characteristics, emotional and behavioral problems of the street adolescent in Bandung.

Methods: A descriptive study was carried out in October-December 2012. From 22 shelters in Bandung, two shelters (RPA GANK and Pesantren Kolong Nurul Hayat) were selected and organized into 4 areas: Cihampelas, 'Samsat', Laswi Street and Kiaracondong. A hundred-seven street adolescents aged 11 to 16 years were participated in this study. They were divided into small groups and filled in the sociodemographic questionnaire and the Indonesian version of standardized Strength and Difficulty Questionnaires (SDQ). Only 100 questionnaires were filled in completely. Data were analyzed using frequency tabulation and bar chart

Results: Sixty-five percent were boys, 53\% were aged 11-13 years, and 53\% were students, $76 \%$ related to more than one sibling, still lived with their families (81\%), and had parents. Their parents had low educational background, had job, and implemented authoritative parenting pattern (41\%). In becoming street adolescent, $63 \%$ were caused by their own motivation, $81 \%$ were children on street, and $55 \%$ had lived in the street more than 5 years. Approximately $27 \%$ of street adolescents were rated as abnormal on the total difficulty score.

Conclusion: Street adolescent in Bandung still have emotional and behavioral problems, which mostly were boys, in the early adolescence stage, school student, had more than one sibling, permissive parenting pattern, and lived in the street for more than 5 years. [AMJ.2015;2(1):172-8]
\end{abstract}

Key words: Emotional and behavioral problems, street Adolescent, Strength and Difficulty Questionnaires (SDQ)

\section{Introduction}

Adolescence is a period of transition between childhood to adulthood, which develops one's biological, psychological, and social changes. This developing period is associated with increased vulnerability to psychopathology. ${ }^{1}$ Estimation of psychiatric disorder is approximately 20 percent of the adolescent population. $^{2}$

Recent research showed that emotional and behavioral problems such as conduct disorder, substance abuse, mood disorder, suicide, eating disorder, anxiety disorder, relational violence, attention deficit/hyperactivity disorder (ADHD), and others uniquely present in adolescent period compared with other developing periods. ${ }^{3}$

Street children or youth/young adolescent is commonly defined as "any girl or boy who has not reached adulthood, for whom the street has become her or his habitual abode and/or sources of livelihood, and who is inadequately protected, supervised, or directed by responsible adults". ${ }^{4}$ According to the United Nation Children's Fund (UNICEF), there are two types of street children: "Children of the street" are homeless children who lived on the street; "Children on the street" earn living on the street and live at home. ${ }^{5}$ Street adolescent is one of psychosocial problems that happens in Indonesia. The term psychosocial problems

Correspondence: Annisa Nurfitriani, Faculty of Medicine, Universitas Padjadjaran, Jalan Raya Bandung-Sumedang Km.21, Jatinangor, Sumedang, Indonesia, Phone: +622261311441 Email: annisa.nurfitriani20@gmail.com 
are meant as a mental illness caused by social influences, such as: socioeconomic status and cultural background. ${ }^{6}$ Stigma and other public opinion about street children and youth make them live socially marginalized. ${ }^{7}$ They live in group and create new sub-culture from street culture, such as theft, drinking, free sex, drug abuse, fighting, and so on. A study of street adolescent in Ukraine discovered that more than $15 \%$ using drugs, $75 \%$ were sexually active, $15 \%$ adolescent were boys and 57\% adolescent were girl working as sex worker , and more than $10 \%$ adolescent were forced to have sex.8 These street youths have limited competence to differentiate positive and negative behavior, they are just internalizing it as they must survive in this certain condition. ${ }^{9}$

These street adolescents are susceptible from negative influencefrom their environment and with their adolescent age make them vulnerable to get psychiatric problem. A study by Pastor et al. $^{10}$ to children 4-17 years old, one most common problem in their age is having emotional and behavioral problem.10 For the reason above, these street youths need psychiatric screening procedures that could help the situation by identifying whether a disorder is present. Additionally, in Indonesia, the research about psychological problems of adolescent street youth is scarce. Therefore, this study aims to describe the characteristic, emotional and behavior problems of street adolescent in Bandung.

\section{Methods}

This descriptive study was carried out in October-December 2012. From 22 shelters in Bandung, two shelters (RPA GANK and Pesantren Kolong Nurul Hayat) were purposively selected by recommendation of Bandung District Social Office. These shelters were organized into 4 areas: Cihampelas, 'Samsat', Laswi Street and Kiaracondong. A hundred-seven street adolescents aged 11 to
16 years were participated in this study. After an explanation about this study, the research was conducted to the head of the shelters, their parents and the street adolescents themselves. Furthermore, informed consent was obtained.

The respondents were divided into small groups and filled in two self-report questionnaires. If they could not understand the questions, the researcher guided in interviewing manner. The questionnaire was divided into two types. First, a questionnaire consisting of sociodemographic aspects: gender, age, education, number of siblings, place of living, parents' information. Second, an Indonesian version of standardized Strength and Difficulty Questionnaires (SDQ).

The SDQ contains 25 sentences that are scored on a three point scale $(0=$ not true, $1=$ somewhat true, $2=$ certainly true). Five subscales score are generated each from 5 questions, those are: hyperactivity/ inattentions, emotional symptoms, conduct problems, peer problems, and prosocial behavior. A total difficulty score is summed from four subscale scores (hyperactivity/ inattentions, emotional symptoms, conduct problems, peer problems). In general, high score represents greater difficulties, except for the prosocial scale score, lower score represents greater difficulties. ${ }^{11}$ (Table 1)

From 107 filled questionnaires, only 100 questionnaires were filled completely. Data were analyzed using frequency tabulation and bar chart.

The Health Research Ethics Committee of Faculty of Medicine, Universitas Padjadjaran, gave ethical approval for the study.

\section{Results}

In total participants of 100 street adolescents, more than half participants were boys $(65 \%)$., $53 \%$ were aged $11-13$ years, and $53 \%$ were still students. From the family factor, mostly (76\%) came from big family, still lived with

Table 1 SDQ Score Interpretation

\begin{tabular}{lccc}
\hline Self Completed & Normal & Borderline & Abnormal \\
\hline Total difficulties score & $0-15$ & $16-19$ & $20-40$ \\
Emotional symptoms & $0-5$ & 6 & $7-10$ \\
Conduct problems & $0-3$ & 4 & $5-10$ \\
Hyperactivity & $0-5$ & 6 & $7-10$ \\
Peer problems & $0-3$ & $4-5$ & $6-10$ \\
Prosocial behavior score & $6-10$ & 5 & $0-4$ \\
\hline
\end{tabular}


Table 2 Characteristics of participants

\begin{tabular}{|c|c|}
\hline Characteristics & Percentage (\%) \\
\hline \multicolumn{2}{|l|}{ Gender } \\
\hline Male & 65.0 \\
\hline Female & 35.0 \\
\hline \multicolumn{2}{|l|}{ Age (years) } \\
\hline $11-13$ & 53.0 \\
\hline $14-16$ & 47.0 \\
\hline \multicolumn{2}{|l|}{ Educational background: } \\
\hline None & 6.0 \\
\hline Drop out & 41.0 \\
\hline -Elementary & $(27.0)$ \\
\hline -Junior high & $(12.0)$ \\
\hline -High school & $(2.0)$ \\
\hline Students at: & 53.0 \\
\hline -Elementary & $(33.0)$ \\
\hline -Junior high & $(14.0)$ \\
\hline -High school & $(6.0)$ \\
\hline \multicolumn{2}{|l|}{ Number of siblings } \\
\hline One & 24.0 \\
\hline$>1$ person & 76.0 \\
\hline \multicolumn{2}{|l|}{ Living with: } \\
\hline Family & 81.0 \\
\hline Surrogate & 11.0 \\
\hline Alone & 8.0 \\
\hline \multicolumn{2}{|l|}{ Father's condition } \\
\hline Alive & 83.0 \\
\hline Died & 11.0 \\
\hline Lost contact & 6.0 \\
\hline \multicolumn{2}{|l|}{ Father: } \\
\hline Has job & 64.0 \\
\hline No job & 36.0 \\
\hline \multicolumn{2}{|c|}{$\begin{array}{l}\text { Father's } \\
\text { background: educational }\end{array}$} \\
\hline Elementary school & 32.0 \\
\hline Junior high school & 52.0 \\
\hline High school & 16.0 \\
\hline \multicolumn{2}{|l|}{ Mother's condition: } \\
\hline Alive & 94.0 \\
\hline Died & 2.0 \\
\hline Lost contact & 4.0 \\
\hline
\end{tabular}

\begin{tabular}{|c|c|}
\hline Characteristics & Percentage (\%) \\
\hline \multicolumn{2}{|l|}{ Mother: } \\
\hline Has job & 50.0 \\
\hline Has no job & 50.0 \\
\hline $\begin{array}{l}\text { Mother's } \\
\text { background: }\end{array}$ & \\
\hline Elementary school & 55.0 \\
\hline Junior high school & 38.0 \\
\hline High school & 7.0 \\
\hline \multicolumn{2}{|l|}{ Parent marital status: } \\
\hline Married live together & 77.0 \\
\hline Married live separate & 5.0 \\
\hline Divorce & 18.0 \\
\hline \multicolumn{2}{|l|}{ Family condition: } \\
\hline Live in harmony & 67.0 \\
\hline No communication & 7.0 \\
\hline Fights & 26.0 \\
\hline \multicolumn{2}{|l|}{ Parenting pattern: } \\
\hline Authoritative & 41.0 \\
\hline Permissive & 34.0 \\
\hline Authoritarian & 18.0 \\
\hline Neglectful & 7.0 \\
\hline \multicolumn{2}{|l|}{ Classification street children: } \\
\hline 'on street' & 81.0 \\
\hline 'of street' & 19.0 \\
\hline \multicolumn{2}{|l|}{ Reason going to street: } \\
\hline Self motivation & 63.0 \\
\hline Forced & 11.0 \\
\hline Environment & 26.0 \\
\hline \multicolumn{2}{|l|}{ Years as street youth: } \\
\hline$<5$ years & 45.0 \\
\hline$>5$ years & 55.0 \\
\hline
\end{tabular}




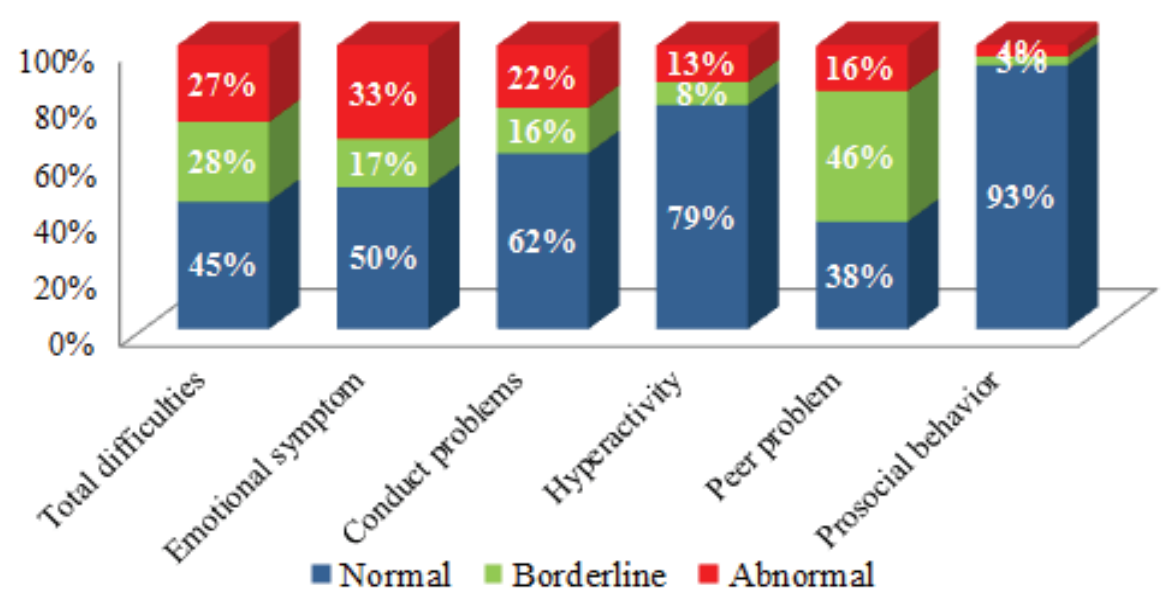

Figure 1 Strengths and Difficulties Questionnaires (SDQ) Result Score

their families (81\%) and had parents, with good condition of family. Mostly their parents had low educational background, had job, conducted authoritative parenting pattern (41\%). In becoming street children/youth, motivation was the most cause (63\%), $81 \%$ were classified as children on street, and 55\% have lived in the street for more than 5 years. (Table 2)

Figure 1 shows the interpretation of score on 5 subscales of Strength and Difficulties Questionnaires on emotional and behavioral problems, the percentages scoring within the borderline, and other ranges. In the abnormal range, the most significant is shown in the subscale of emotional symptom (33\%) and in the borderline range is significaltly shown in peer problem subscale $(46 \%)$.

Approximately $27 \%$ of street adolescents were rated as abnormal on total difficulties score. From street adolescents who had abnormality, $16 \%$ were males,, in the early adolescent stage (16\%), with more than 5 years have lived in street $(15 \%)$. No distinct differences discovered in educational background category between drop out $(12 \%)$ and student $(13 \%)$. However, the proportion of emotional and behavioral problem were varied by family categories: mostly lived in harmonious family (17\%), had more than one siblings (24\%), and implemented permissive parenting pattern $(11 \%)$.

\section{Discussions}

The study revealed that $27 \%$ street adolescents in Bandung had abnormal on total difficulties score, $33 \%$ with abnormal on the emotional symptoms. A similar study in Zambia12 reported that from $27 \%$ of children were rated abnormal on total difficulties score, $47.6 \%$ were abnormal on emotional symptoms.

In gender differences was discovered that boys had higher proportion than girls. It is found that boys tend to exhibit more externalizing behavior in the early age (e.g: aggressive, forceful, and oppositional behaviors) that are risk factors for the development of more serious emotional and behavioral problems. ${ }^{13}$

Compared to the adolescence stage, early adolescent had higher proportion than middle adolescent. During the early adolescence (10 through 14 years old) is an initial transition period of children to undergo many physical, emotional, and mental changes. Children and parents, somehow, are often unprepared and just to get it through. This period is associated to increased risk of poor mental health, such as: some mood disorders, eating disorders, substance use, self-harm, and suicidal behavior. ${ }^{2,14}$

The obvious differences among the educational background of adolescent street youth were observed between participants who never went to school and participants who were still/ever in school. Few studies have explored the differences of educational background on emotional and behavioral problems. However, according to the interview, they are more likely to have social problem with peer, while they are bullied most of the time at their school.

Participants with more than one sibling demonstrated a higher proportion compared to other participant with one sibling. It is 


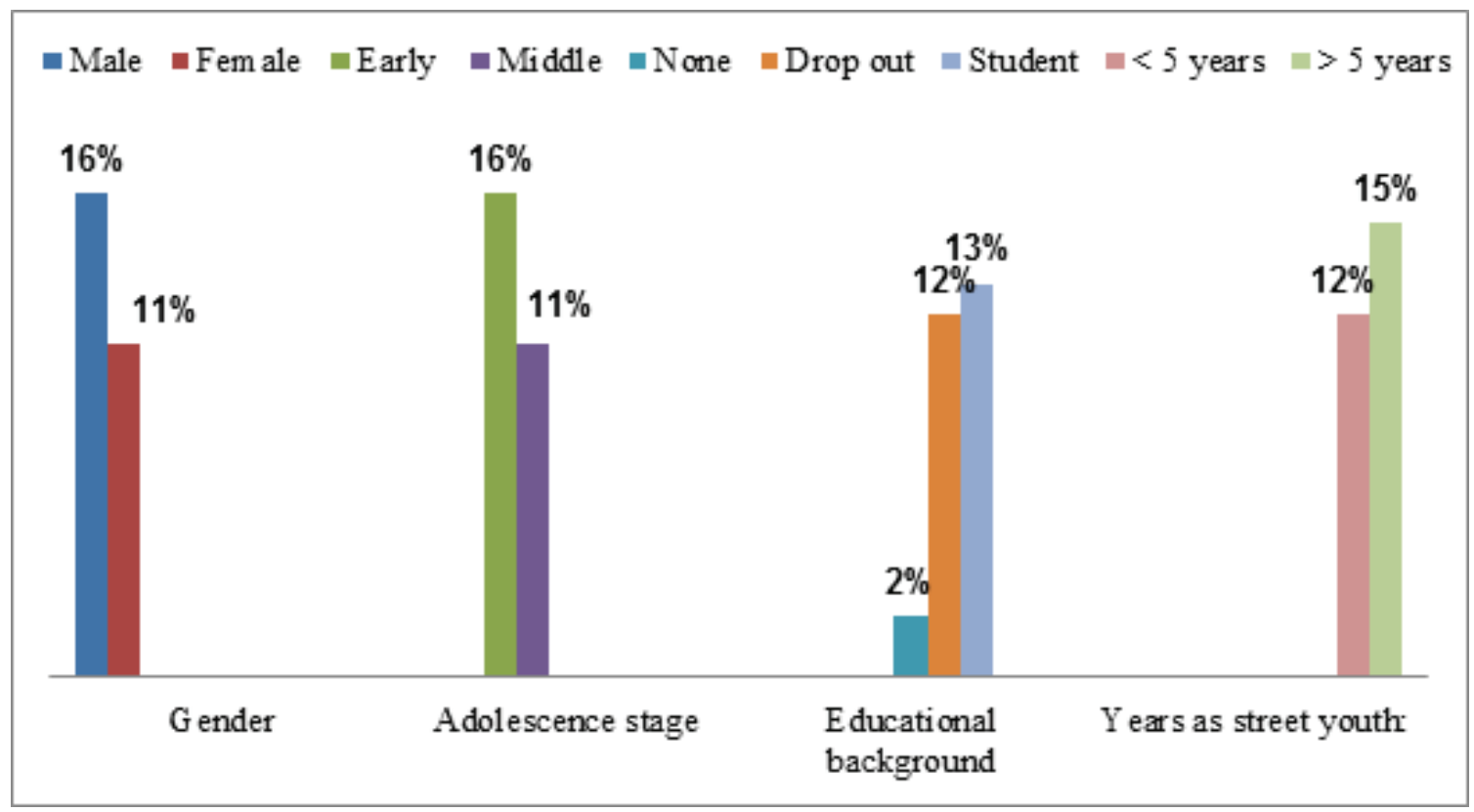

Figure 2 Proportion of Emotional and Behavioral Problems in Adolescent Street Aged 1116 Years By Gender, Adolescent Stage, Educational Background, and Years As Street Youth

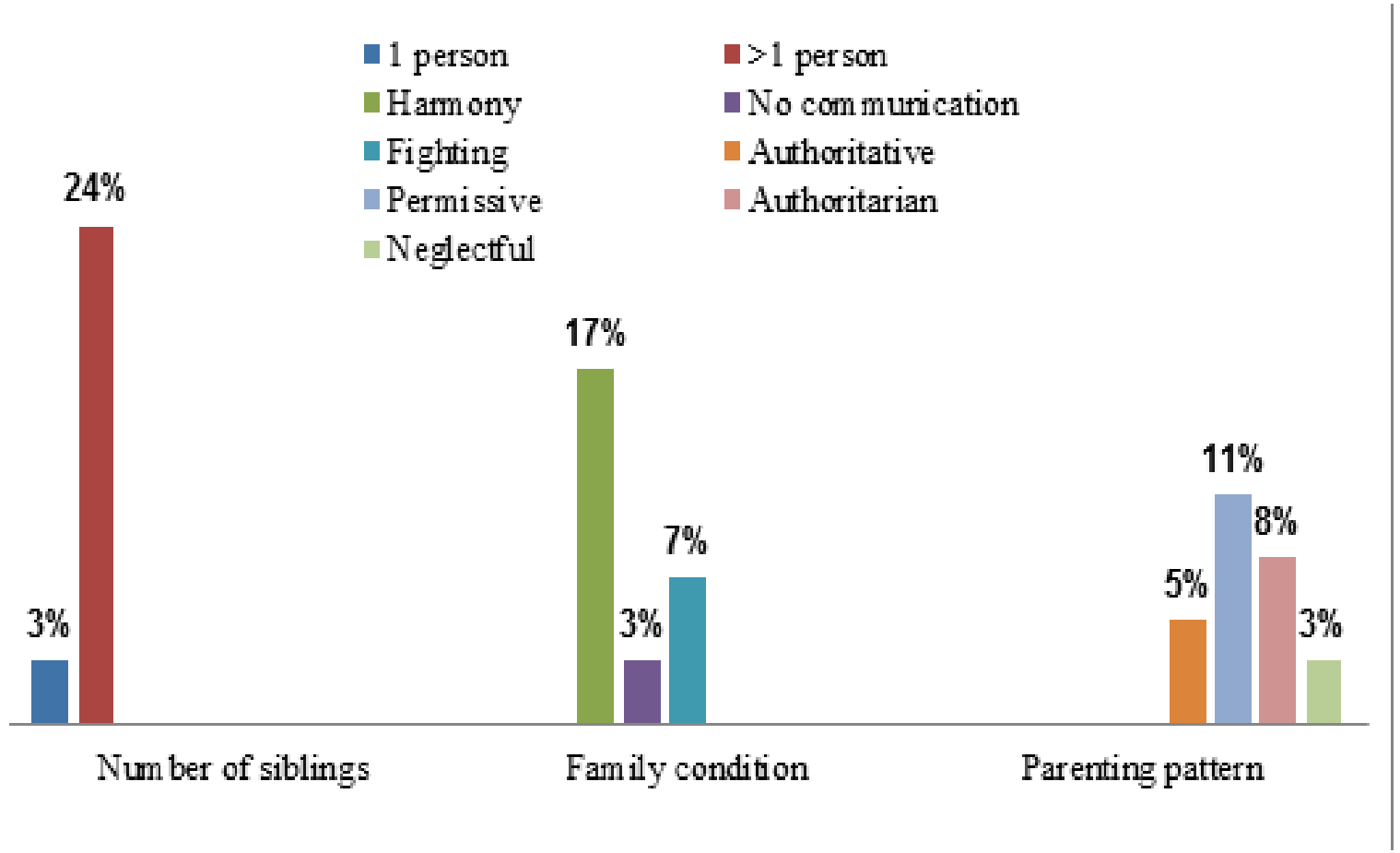

Figure 3 Proportion of Emotional and Behavioral Problems in Adolescent Street Youth Aged 11-16 Years by Number of Siblings, Family Condition, and Parenting Pattern 
suspected that large family size contributes to behavioral and emotional problems. Former study revealed that large family size was associated with increasing risk of psychiatric morbidity, by the existence of the older and younger siblings. ${ }^{15}$

Surprisingly, family in harmony condition had higher proportion on emotional and behavioral problem. Likely, family factor is not a main influence for adolescence. Study about parent-child connectedness among adolescent shows that they had difficulty talking to their parents and valuing their peer's opinion is associated with their emotional and behavioral problems. ${ }^{16}$

According to Baumrind ${ }^{17}$, there are 4 categories of parenting pattern: authoritative, authoritarian, permissive, and neglectful. In this study, it is suspected that permissive parenting pattern has caused emotional and behavioral problems compared to other parenting patterns. Research findings show that authoritarian and permissive parenting have consistently negative outcome and authoritative parenting show positive outcome.

Street adolescent living or working on the street for more than 5 years had higher proportion in having emotional and behavioral problems. The longer they live on street, the more they are internalizing the negative influence from street subculture. ${ }^{9}$ Furthermore, the stressful life that street adolescent has been through makes them at risk on having sort of psychiatric disorder, emotional problem, and others. ${ }^{5}$

From this study, it can be concluded that $27 \%$ of street adolescents have emotional and behavioral problems, which mostly are boys. The problems occurs to those who are in the early adolescence stage, school student, have more than one siblings, receive permissive parenting pattern, and live in the street for more than 5 years.

The limitation of this study is the correlation among sociodemographic characteristics of the respondents, behavioral and emotional problems were not conducted.

\section{References}

1. Paus T, Keshavan M, Giedd J. Why do many psychiatric disorder emerge during adolescence?. Nat Rev Neurosci. 2008;9(12):947-57.

2. Sadock BJ, Sadock VA. Kaplan \& sadock's synopsis of psychiatry: behavioral sciences/clinic psychiatry. 10th ed.
Philadelphia: Lippincott Williams \& Wilkins; 2007.

3. Wolfe AD, Mash JE, editors. Behavioral and emotional disorders in adolescent. New York: The Guilford Press; 2006.

4. Inter-NGO programme on street children and street youth, sub regional seminar for the mediterranean. summary of proceedings; 1983 October 24-27. Marseilles: 1983.

5. WHO. A profile of street children : a training package on substance use, sexual and reproductive health including HIV/AIDS and STDs. 2000 [Cited 2013 February 11]. Available from: http://whqlibdoc.who. int/hq/2000/WHO_MSD_MDP_00.14_ Module1.pdf

6. Kementerian Kesehatan Republik Indonesia. Masalah psikososial. 2008 [Cited 2013 February 3]. Available from: http://www.depkes.go.id/downloads/ Psikososial.PDF.

7. Benitez Sd. The state of the world's children 2012. New York: UNICEF; 2012.

8. Busza JR, Balakireva OM, Teltschik A, Bondar TV, Sereda YV, Meynell C, et al. Street-based adolescents at high risk of HIV in Ukraine. J Epidemiol Community Health. 2011; 65(12): 1166-70.

9. Saripudin D, Suwirta A, Komalasari K. Resocialization of street children at open house: a case study in the city of Bandung, Indonesia. EDUCARE: International Journal for Educational Studies. 2008;1(1):91102.

10. Pastor PN, Reuben CA, Duran CR. Identifying emotional and behavioral problems in children aged 4-17 years: United States, 2001-2007. Natl Health Stat Reports. 2012;(48):1-17.

11. SDQ Information for researchers and proffesionals about the Strength and Difficulties Questionnaires. What is the SDQ?. 2008; [Cited 2013 February 4]. Available from: http://www.sdqinfo.org.

12. Imasiku ML, Banda S. Mental health problems in residential care for street children. Med J Zambia. 2010;37(3):174-9.

13. Hill AL, Degnan KA, Calkins SD, Keane SP. Profiles of externalizing behavior problems for boys and girls across preschool: the roles of emotion regulation and inattention. Dev Psychol. 2006;42(5):913-28.

14. Spellings M. Helping your child through early adolescence. Washington D.C: U.S Departerment of Education; 2005.

15. Riordan DV, Morris C, Hattie J, Stark C. Family size and perinatal circumstances, 
as mental health risk factor in a Scottish birth cohort. Soc Psychiatry Psychiatr Epidemiol. 2012;47(6):975-83

16. Ackard DM, Neumark-Sztainer D, Story M, Perry C. Parent-child connectedness and behavioral and emotional health among adolescents. Am J Prev Med. 2006;30(1):59-66.

17. Baumrind D. The influence of parenting style on adolescent competence and substance use. J Early Adolesc. 1991;11(1): 56-95. 